\title{
Analisis numerik perilaku lentur balok yang diperkuat dengan GFRP dan wiremesh
}

\author{
Mohd Isneini ${ }^{\text {a,*, }}$, Fikri Alami ${ }^{\mathrm{b},}$ Nadya Agustina ${ }^{\mathrm{c}}$ \\ a Jurusan Teknik Sipil, Universitas Lampung, Jl. Soemantri Brojonegoro No. 1 Bandar Lampung, 35145, Indonesia \\ b Jurusan Teknik Sipil, Universitas Lampung, Jl. Soemantri Brojonegoro No. 1 Bandar Lampung, 35145, Indonesia \\ ${ }^{c}$ Mahasiswa Program Studi S1 Teknik Sipil, Universitas Lampung, Jl. Soemantri Brojonegoro No. 1 Bandar Lampung, 35145, Indonesia
}

\section{H I G H L I G H T S}

- Penelitian terhadap penggunaan lembaran GFRP dan wiremesh sebagai kombinasi perkuatan.

- Analisis numerik dilakukan sebagai perbandingan kajian eksperimental.

- Pemodelan berbasis elemen hingga

\section{N F O A R T I K E L}

\section{Riwayat artikel:}

Diterima 12 Maret 2020

Diterima setelah diperbaiki 18 April 2020

Diterima untuk diterbitkan 21 April 2020

Tersedia secara online 1 Agustus 2020

\section{Kata kunci:}

Beton,

GFRP,

pemodelan,

perkuatan,

wiremesh.

\begin{abstract}
A B S T R A K
Penelitian ini menggunakan tiga jenis balok yaitu balok tanpa perkuatan (B1), balok dengan perkuatan kombinasi GFRP dan Wiremesh (B2) dan balok dengan perkuatan Wiremesh saja (B3) dengan analisis numerik elemen hingga. Dalam memodelkan beton dan GFRP dideskripsikan sebagai elemen solid, kemudian untuk model tulangan dan wiremesh sebagai elemen truss dan model epoksi sebagai elemen cohesive. Interaksi yang diberikan pada hubungan antara tulangan dan beton serta hubungan antara epoksi dan wiremesh menggunakan teknik interaksi embedded region kemudia pada hubungan lapisan perkuatan dan lapisan epoksi menggunakan teknik interaksi tie constraint. Berdasarkan input beban maksimum hasil eksperimental, perbedaan persentase regangan pada model balok B1 sebesar 2\% antara model numerik dan eksperimental, pada balok B2 adalah sebesar 30\% dan pada balok B3 adalah sebesar 30\%.
\end{abstract}

Diterbitkan oleh Jurusan Teknik Sipil Universitas Lampung

\section{Pendahuluan}

Banyak penelitian yang berfokus pada simulasi perilaku beton bertujuan untuk menemukan kondisi kritis saat beton dikenakan beban. Perkembangan ilmu pengetahuan di era digital saat ini, memunculkan metode baru yang dapat mempermudah pekerjaan salah satunya yakni simulasi perilaku balok beton bertulang yang diperkuat dengan kombinasi GFRP dan wiremesh dengan bantuan software. Data dan hasil dari studi eksperimental yang telah dilakukan dapat juga di evaluasi dengan melakukan pemodelan struktur. Salah satu pendekatan dengan pemodelan yang dapat dilakukan yaitu dengan software berbasis simulasi metode numerik elemen hingga. Hasil pemodelan dari software ini akan divalidasi dengan hasil

\footnotetext{
* Penulis koresponden

Alamat e-mail: mohd.isneini@eng.unila.ac.id (M. Isneini)

Peer review dibawah tanggung-jawab Jurusan Teknik Sipil

Universitas Lampung.

https://doi.org/10.23960/rekrjits.v24i2.4
}

studi eksperimental yang telah dilakukan oleh Vernanda [1] yang menggabungkan penggunaan GFRP dengan wiremesh dan Akbar [2] yang memperkuat balok dengan wiremesh.

\section{Metode Penelitian}

Dua model terdiri atas model eksperimental sebagai referensi pemodelan dan model numerik hasil dari pendekatan menggunakan software. Penetapan model untuk simulasi numerik sudah tervalidasi dengan hasil dari percobaan eksperimental.

\section{Penetapan Model}

Pada pemodelan, dibuat model pendekatan dengan mendekati proses sebenarnya di laboratorium. Setelah proses laminasi dengan lem epoksi mengering, selanjutnya komposit perkuatan diberi lem epoksi kembali untuk proses pelekatan dengan struktur balok beton. Perkuatan yang dipasang memiliki panjang $1440 \mathrm{~mm}$ dan lebar 150 mm. Model balok B1 adalah balok beton tanpa perkuatan, 
balok B2 diperkuat dengan kombinasi dua lembar GFRP dan dua lembar komposit wiremesh yang mempunyai tebal total sebesar $5.20 \mathrm{~mm}$. Balok B3, diperkuat dengan dua lembar komposit wiremesh dengan tebal perkuatan sebesar 3.33 mm. Sedangkan, untuk epoksi diberikan ketebalan sebesar $1 \mathrm{~mm}$. Pada software tentunya didefinisikan dimensi balok, beserta bagian-bagiannya, parameter nilai tegangan, kondisi batas tumpuan dan sebagainya sehingga terjalin Interaksi antar elemen beton, epoxy, GFRP, dan wiremesh pada software tersebut.

Atas alasan efisiensi pekerjaan, model balok pada software disederhanakan menjadi model 1/4 balok, karena balok simetris ditinjau dari struktur, tumpuan dan beban, seperti terlihat pada Gambar 1 dan Gambar 2.

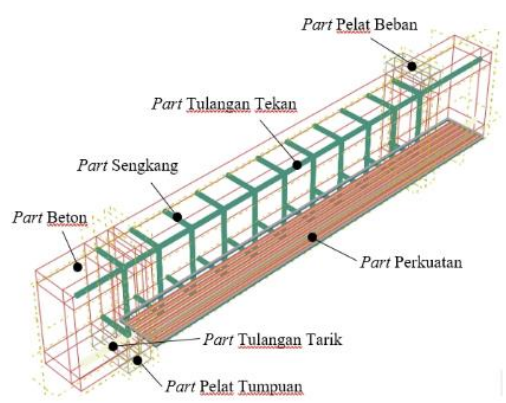

Gambar 1 Model penampang balok dengan perkuatan

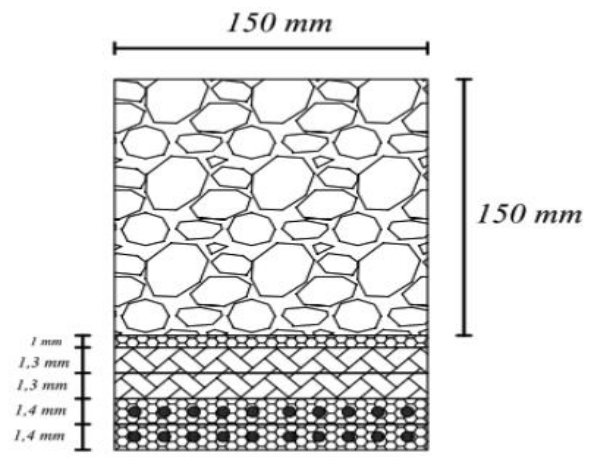

(a) Penampang balok dengan perkuatan GFRP dan wiremesh

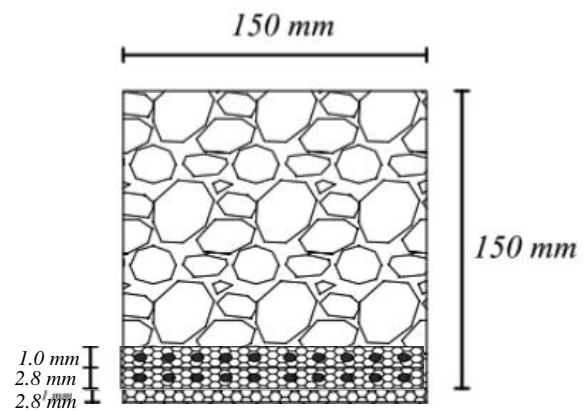

(b) Penampang balok dengan perkuatan wiremesh

Gambar 2 Pendekatan pemodelan balok perkuatan (a dan b)

\section{Material Properties}

Dalam memodelkan material beton, ada dua mekanisme kegagalan yaitu gagal tarik dan kehancuran tekan. Perilaku tegangan-regangan beton dalam model tekan dimodelkan menggunakan konstitutif hubungan yang mengacu pada Hsu dan Hsu [3]. Metode pendekatan crack-opening- displacement digunakan dalam pemodelan respon tarik beton, karena metode ini dianggap paling praktis dan sesuai. Konstitutif model menggunakan hubungan stressdisplacement yang mengacu pada CEB-FIP [4]. Perilaku tegangan-perpindahan bilinear dalam pemodelan epoksi menggunakan konstitutif hubungan yang mengacu pada Lu dkk. [5]. Adapun model konstitutif material dapat dilihat pada Gambar 3.

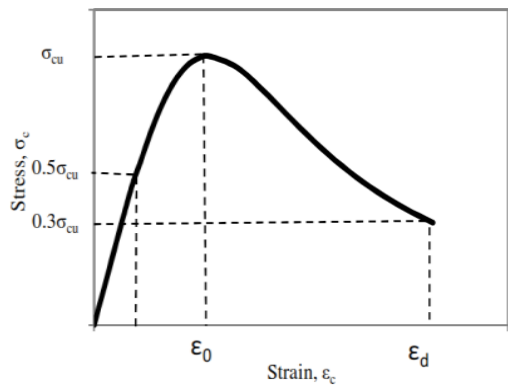

(a) kehancuran tekan material beton

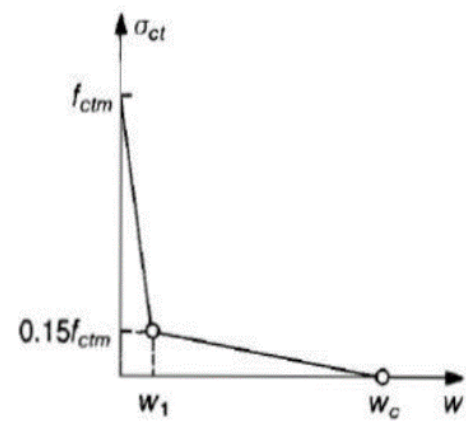

(b) kegagalan tarik material beton

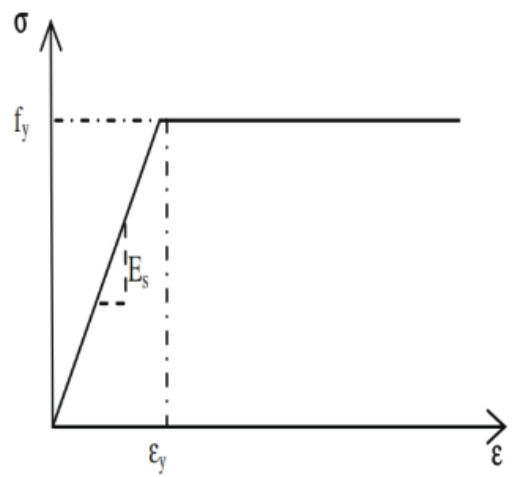

(c) tegangan-regangan tulangan dan wire mesh

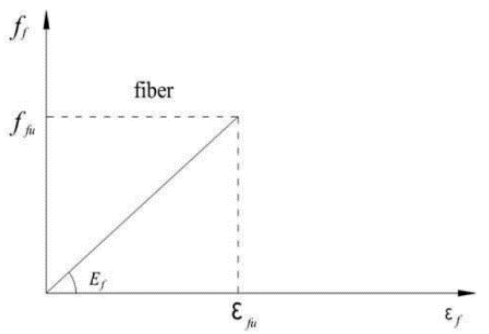

(d) Tegangan-regangan FRP 


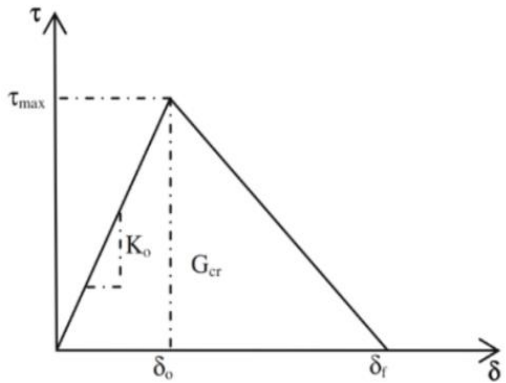

(d) Bilinear traction-separation epoksi.

Gambar 3 Konstitutif material

Selanjutnya, disajikan persamaan-persamaan yang berkaitan dalam material serta bilinear epoxy:

\subsection{Material beton kehancuran tekan}

Persamaan-persamaan yang dipakai adalah sebagai berikut:

$$
\begin{gathered}
\sigma_{c}=\left(\frac{\beta\left(\frac{\varepsilon_{c}}{\varepsilon_{0}}\right)}{\beta-1+\left(\frac{\varepsilon_{c}}{\varepsilon_{0}}\right)^{\beta}}\right) \sigma_{c u} \\
\beta=\frac{1}{1-\left(\frac{\varepsilon_{c u}}{(\varepsilon 0 E 0)}\right)} \\
\varepsilon_{o}=8,9 \times 10^{-5} \sigma_{c u}+2,114 \times 10^{-3} \\
E_{o}=1,2431 \times 10^{2} \sigma_{c u}+3,28312 \times 10^{3}
\end{gathered}
$$

dengan catatan, pada rumus di atas $\sigma_{c}, \sigma_{c u}$ dan $E_{o}$ dalam satuan kip/in ${ }^{2}$ (konversi faktor: $1 \mathrm{MPa}=0,145037743$ $\mathrm{kip} / \mathrm{in}^{2}$ ).

\subsection{Material beton kegagalan tarik}

Persamaan yang dipakai adalah Persamaan 5 sampai Persamaan 9.

$$
\begin{gathered}
f_{t}=f_{c t m}\left(1-0,85 \frac{w}{w_{1}}\right) \quad f_{c t m}=0,15 f_{c t m} \leq f_{t} \leq f_{c t m} \\
f_{t}=\frac{0,15 f_{c t m}}{w_{c}-w_{1}}\left(w_{c}-w\right) \quad f_{c t m}=0 \leq f_{t} \leq 0,15 f_{c t m} \\
w_{1}=2 \frac{G_{f}}{f_{c t m}}-0,15 w_{c} \\
w_{c}=a_{f} \frac{G_{f}}{f_{c t m}} \\
f_{c t m}=f_{c t k o}, m\left(\frac{f_{c k}}{f_{c k o}}\right)^{2 / 3}
\end{gathered}
$$

dengan nilai dari $f_{\text {ctko }}, m$ diambil sebesar 1,4 MPa dan $f_{\text {cko }}$ sebesar $10 \mathrm{MPa}$. $w$ mewakili crack opening $(\mathrm{mm}), w_{1}$ adalah crack opening pada $\left(f_{t}=0,15 f_{c t m}\right), w_{c}$ adalah crack opening pada poin kegagalan total $\left(f_{t}=0\right)$ dan $G_{f}$ adalah fraktur energi yang dihitung berdasarkan Persamaan 10.

$$
G_{f}=G_{f 0}\left(\frac{f_{c m}}{f_{c m 0}}\right)^{0,7}
$$

dengan nilai $f_{c m 0}$ diambil sebesar $10 \mathrm{MPa} . f_{c m}$ adalah nilai rata-rata dari kuat tekan beton dan dapat diekspresikan sebagai fungsi dari kuat tekan beton karakteristik, $f_{c k}$ yang ditunjukkan pada Persamaan 11.

$$
f_{c m}=f_{c k}+\Delta f
$$

dengan $\Delta_{f}$ diambil sebesar $8 \mathrm{MPa}$. Reineck $d k k$ [6] menyarankan untuk kuat tekan beton karakteristik, $f_{c k}$ dapat dihitung sebagai fungsi dari kuat silinder beton, $f_{c}^{\prime}$ yang ditunjukkan pada Persamaan 12.

$$
f_{c k}=f^{\prime}{ }_{c}-1,6
$$

untuk $G_{f o}$ yang merupakan nilai dasar dari fraktur energi, bergantung pada ukuran agregat maksimum, $d_{\max }$ dimana nilainya disajikan pada Tabel 1 .

Tabel 1

Nilai dasar fraktur energi, $G_{f o}[4]$

\begin{tabular}{lll}
\hline$d_{\max }(\mathrm{mm})$ & $G_{f_{o}}\left(\mathrm{Nmm} / \mathrm{mm}^{2}\right)$ & $\alpha_{f}$ \\
\hline 8 & 0,025 & 8 \\
16 & 0,030 & 7 \\
32 & 0,058 & 5 \\
\hline
\end{tabular}

Pada model penelitian ini, besar $G_{f o}$ diambil nilai 0,025 sedangkan untuk nilai koefisien, $\alpha_{f}$ diambil nilai 8 berdasarkan ukuran agregat maksimum pada sampel uji percobaan laboratorium.

\subsection{Material bilinear epoksi}

Persamaan-persamaan yang dipakai adalah sebagai berikut:

$$
\begin{gathered}
T=\tau_{\max } \sqrt{\frac{s}{s_{o}}} \quad s \leq s_{o} \\
\tau=\tau_{\max } \frac{s_{f}-s}{s_{f}-s_{o}} \quad s_{o}<s<s_{f} \\
\tau=0 \quad s>s_{f} \\
s f=\frac{2 G_{f}}{\tau_{\max }}
\end{gathered}
$$

dengan,

$$
\tau_{\max }=\frac{N_{f \max }}{L_{e} b_{f}}
$$

$$
N_{f \max }=a_{1} c_{1} k_{c} k_{b} b_{c} \sqrt{n_{f} t_{f} E_{f} f^{\prime}}
$$$$
L_{e}=\sqrt{n_{f} t_{f} E_{f}} \sqrt{c_{2} f^{\prime} t}
$$

$$
f^{\prime} t=0,18 f^{\prime} c^{\frac{2}{3}}
$$$$
S_{o}=0,0195 \beta_{w} f^{\prime}{ }_{t}
$$

$$
G f=0,308 \beta_{W}^{2} \sqrt{f^{\prime}}
$$

$$
\begin{gathered}
\beta w=\sqrt{\frac{2,25-\frac{b_{f}}{b_{c}}}{1,25+\frac{b_{f}}{b_{c}}}} \\
K_{n n}=\alpha \frac{E}{t} \\
\frac{K_{s s}}{K_{t t}}=\alpha \frac{G_{c}}{t}
\end{gathered}
$$

\section{Hasil dan Pembahasan}

Setelah dilakukan plot data dan dibandingkan dengan data hasil studi eksperimental maka dapat disajikan hubungan beban dan regangan pemodelan dan hasil ekperimental balok beton bertulangan dengan perkuatan yang ditunjukkan dalam Gambar 4, Gambar 5 dan Gambar 6. 


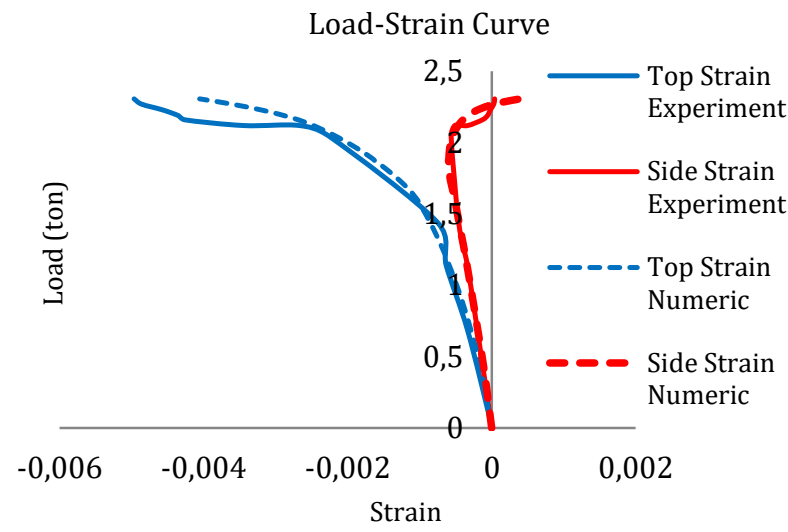

Gambar 4 Hubungan beban dan regangan Balok B1

Regangan pada balok B1 bagian atas dengan beban input sebesar 2,307 ton pada simulasi numerik diperoleh nilai sebesar -0,00405517 sedangkan pada eksperimental diperoleh nilai sebesar -0,004966. Regangan pada balok normal pada bagian sisi samping pada simulasi numerik, struktur beton mengalami tarik sehingga regangan bernilai positif sebesar 0,00039741 pada beban sebesar 2,307 ton, nilai tersebut lebih kecil dibandingkan dengan regangan tarik $\left(\varepsilon_{t}\right)$ teori maksimum yang didapat sebesar 0,01672 . Hal ini disebabkan oleh baja tulangan yang telah mengalami leleh sehingga balok sudah tidak bisa menahan beban. Sedangkan pada eksperimental, struktur beton mengalami tarik sehingga regangan bernilai positif sebesar 0,000041 pada beban sebesar 2,307 ton. Hal ini disebabkan oleh baja tulangan yang telah mengalami leleh sehingga balok sudah tidak bisa menahan beban dan strain gauge tidak bisa membaca regangan yang terjadi. Simulasi numerik yang dilakukan dengan input nilai beban yang senilai dengan eksperimental menghasilkan perilaku lentur yang mendekati nilai regangan dari eksperimental pada regangan beton namun tidak mencapai besar regangan seperti hasil eksperimental namun hal ini dikesampingkan mengingat besar lendutan yang sudah bersesuaian dan untuk regangan beton sudah mencapai regangan 0,003 sudah dianggap beton mengalami kehancuran.

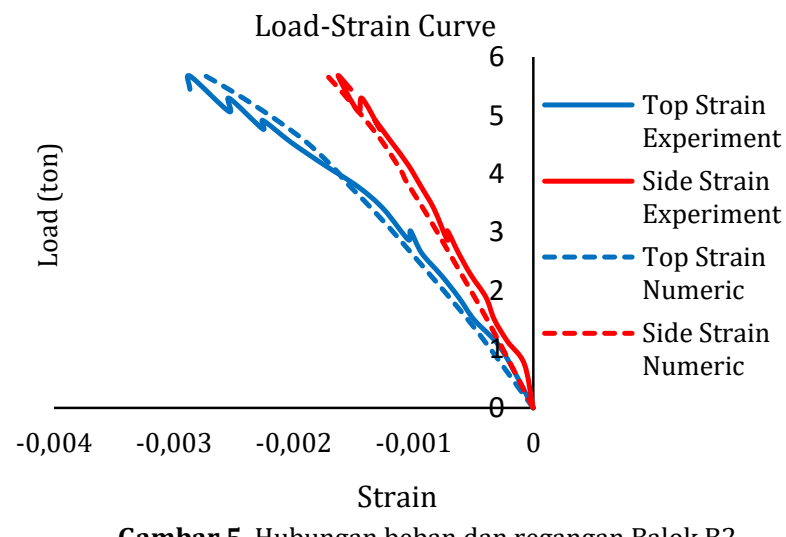

Regangan pada balok B2 bagian atas dengan beban input sebesar 5,675 ton pada simulasi numerik diperoleh nilai sebesar $-0,0027321$ sedangkan pada eksperimental diperoleh nilai sebesar $-0,002864$. Besar nilai regangan yang diperoleh pada percobaan eksperimental dan pemodelan sesuai dengan model kehancuran yang terjadi yaitu kegagalan pada lekatan sehingga regangan beton belum mencapai regangan 0,003. Regangan pada balok B2 pada bagian sisi samping pada simulasi numerik diperoleh nilai akhir sebesar $-0,0017162$ sedangkan pada eksperimental diperoleh nilai akhir sebesar -0,00152. Simulasi numerik yang dilakukan dengan input nilai beban yang senilai dengan eksperimental menghasilkan perilaku lentur yang mendekati nilai regangan pada eksperimental pada regangan beton bagian atas dan samping balok beton.

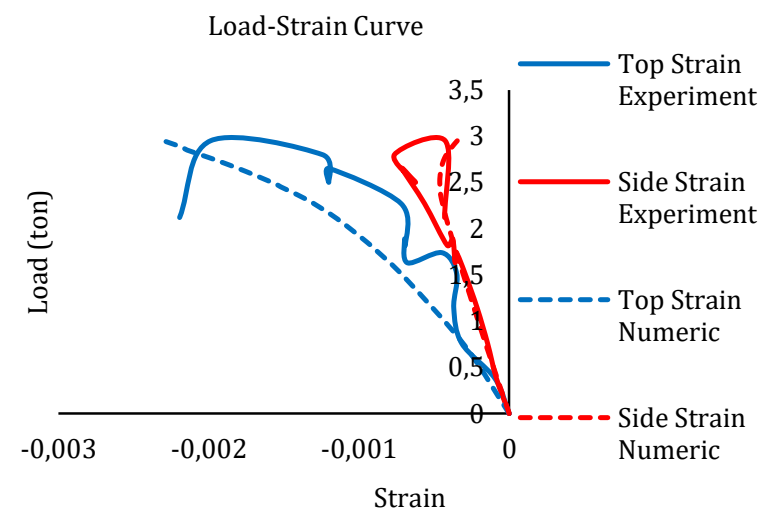

Gambar 6 Hubungan beban dan regangan Balok B3

Regangan pada balok B3 bagian atas dengan beban input sebesar 2,95 ton pada simulasi numerik diperoleh nilai sebesar $-0,0023008$ sedangkan pada eksperimental diperoleh nilai sebesar -0,002194. Besar nilai regangan yang diperoleh pada percobaan eksperimental dan pemodelan sesuai dengan model kehancuran yang terjadi yaitu kegagalan pada lekatan dengan patahan di bagian tengah perkuatan sehingga regangan beton belum mencapai regangan 0,003. Regangan pada balok B3 pada bagian sisi samping pada simulasi numerik diperoleh nilai akhir sebesar -0,00034577 sedangkan pada eksperimental diperoleh nilai akhir sebesar -0,00043. Simulasi numerik yang dilakukan dengan input nilai beban yang senilai dengan eksperimental menghasilkan perilaku lentur yang mendekati nilai regangan pada eksperimental pada regangan beton bagian atas dan samping balok beton. Perbedaan persentase regangan pada model balok B1 sebesar $2 \%$ antara model numerik dan eksperimental, pada balok B2 adalah sebesar 30\% dan pada balok B3 adalah sebesar 30\%. Adapun rangkuman hasil uji hubungan beban - regangan, disajikan pada Table 2.

Tabel 2

Hasil beban-regangan pemodelan dan eksperimental

\begin{tabular}{lllll}
\hline Model & $\begin{array}{l}\text { Beban } \\
\text { (ton) }\end{array}$ & Sisi balok & $\begin{array}{l}\text { Regangan } \\
\text { numerik }\end{array}$ & $\begin{array}{l}\text { Regangan } \\
\text { Eksperimental }\end{array}$ \\
\hline \multirow{2}{*}{ B1 } & 2,307 & Atas & $-0,00405517$ & $-0,004966$ \\
& & Samping & 0,00039741 & 0,000041 \\
B2 & 5,675 & Atas & $-0,0027321$ & $-0,002864$ \\
B3 & 2,95 & Samping & $-0,0017162$ & $-0,00152$ \\
& & Atas & $-0,0023008$ & $-0,002194$ \\
& & Samping & $-0,00034577$ & $-0,00043$ \\
\hline
\end{tabular}

\section{Simpulan}

Grafik hubungan beban dan regangan perbandingan antara hasil pemodelan dengan hasil eksperimental untuk model balok tanpa perkuatan (B1) dan balok dengan 
perkuatan GFRP dan Wiremesh (B2) serta balok dengan perkuatan Wiremesh (B3) memiliki perilaku yang serupa. Hasil yang diperlihatkan pada pemodelan didapat nilai regangan yang lebih kecil dibandingkan dengan hasil eksperimental namun sudah memenuhi syarat yang ditentukan untuk balok tanpa perkuatan (B1) mencapai regangan beton $\left(\varepsilon_{c}\right)$ 0,003 dan balok beton-perkuatan (B2) dan (B3) dibawah regangan beton $\left(\varepsilon_{c}\right) 0,003$ karena terjadi kegagalan lekatan beton dan perkuatan. Berdasarkan perilaku lentur untuk hubungan beban dan regangan yang didapat pada pemodelan balok beton yang dimodelkan, dapat disimpulkan bahwa parameter mekanis material seperti elastic dan plastic properties yang diterapkan pada pemodelan program sudah sesuai dengan keadaan aktual benda uji.

\section{Daftar Pustaka}

[1] Vernanda, D.: Studi eksperimental perkuatan balok beton bertulang dengan mengkombinasikan penggunaan bahan tambahan wiremesh dan GFRP pada beton mutu normal. Skripsi. Jurusan Teknik Sipil Fakultas Teknik. Universitas Lampung, Bandar Lampung, 2019

[2] Akbar, C.F.: Studi eksperimental perkuatan balok beton bertulang dengan kombinasi GFRP dan wiremesh. Skripsi. Jurusan Teknik Sipil Fakultas Teknik. Universitas Lampung, Bandar Lampung, 2019

[3] Hsu, L.S. dan Hsu, C.: Complete stress-strain behaviour of high-strength concrete under compression. Magazine of Concrete Research, 46, 1994, 301-312

[4] CEB-FIP-1990. CEB-FIP Model Code 1990. Comite EuroInternational du Beton, London, 1990

[5] Lu, X.Z., Teng, J.G., Ye, L.P., Jiang, J.J.: Bond-slip models for sheets/plates bonded to concrete. Engineering Structures, 27, 6, 2005, 938-950.

[6] Reineck K.H., Kuchma D.A., Kang S.K., Marx, S,: Shear data base for reinforced concrete members without shear reinforcement. ACI Structural Journal, 100, 2, 2003, 240-249 